\title{
Penerapan Metode Waterfall Dalam Perancangan Sistem Informasi Ujian Pada SMK Indonesia Global Berbasis Web
}

\author{
Achmad Rifai ${ }^{[1]}$, Yasinta Prabawati Yuniar ${ }^{[2]}$ \\ Program Studi Teknik Informatika, STMIK Nusa Mandiri [1] \\ Jalan Damai No. 8 Warung Jati Barat (Margasatwa) Jakarta Selatan \\ Program Studi Sistem Informasi Akuntansi, Universitas Bina Sarana Informatika ${ }^{[2]}$ \\ Jalan SMA Kapin No. 292A Kalimalang Jakarta Timur \\ Email : achmad.acf@nusamandiri.ac.id [1], yasintayuniar290292@gmail.com [2]
}

\begin{abstract}
ABSTRAKSI
Dalam era digitalisasi pemanfaatan teknologi informasi dapat dirasakan hampir dalam semua bidang seperti bidang kesehatan, perbankan, budaya dan pendidikan. Dalam dunia pendidikan penerapan teknologi informasi sangat diperlukan baik dalam kegiatan belajar mengajar maupun dalam penilaian ujian siswa-siswi. Dalam penilaian ujian pada sekolah menengah kejuruan Indonesia Global Depok masih mengunakan ujian pada umumnya dimana guru membagikan kertas soal ujian dan siswa menjawab soal yang diberikan oleh guru pada selembar kertas yang sudah disediakan. Dengan ujian secara konvensional ini sering menimbulkan permasalahan seperti guru terlambat membuat rapor nilai karena guru harus mengoreksi jawaban siswa satu persatu. Sistem informasi ujian dalam bentuk online berbasis web dapat membantu memberikan solusi terhadap permasalahan yang berhubungan dengan penilaian siswa. Dalam pembuatan sistem informasi ujian berbasis web menggunakan metode waterfall yang terdiri dari analisis, desain, pengkodean dan pengujian serta entity relationship diagram dalam merancang database. Dengan adanya sistem informasi ujian berbasis website dapat mempermudah guru dalam pengolahan data nilai siswanya agar lebih efektif dan efisien dalam pembuatan laporan nilai.
\end{abstract}

Kata Kunci: Sistem Informasi, Ujian Berbasis Web, Metode Waterfall.

\section{ABSTRACT}

In the digitalization era, the use of information technology can be felt in almost all fields such as health, banking, culture and education. In the world of education the application of information technology is needed both in teaching and learning activities and in the assessment of student examinations. In the assessment of examinations at the Indonesian Global Vocational High School, Depok still uses general tests where the teacher distributes exam paper and students answer the questions given by the teacher on a piece of paper provided. With conventional examinations this often causes problems such as teachers late making report cards because teachers must correct students' answers one by one. An online web-based exam information system can help provide solutions to problems related to student assessment. In making web-based exam information systems using the waterfall method consisting of analysis, design, coding and testing as well as entity relationship diagrams in designing databases. With the existence of a website-based exam information system can facilitate teachers in processing student value data to be more effective and efficient in making value reports.

Keyword: Information System, Web Based Exams, Waterfall Methods.

\section{PENDAHULUAN}

Seiring dengan perkembangan teknologi informasi (TI) yang semakin pesat, kebutuhan akan suatu konsep dan mekanisme belajar mengajar berbasis TI menjadi tidak dapat dihindarkan terutama dalam dunia pendidikan (Suharyanto \& Mailangkay, 2016). Pemanfaatan teknologi informasi yang memberikan nilai positif perlu dilakukan dalam pendidikan diantaranya kegiatan belajar mengajar dan ujian siswa didalam sekolah. Kegiatan ujian memiliki tujuan sebagai bahan evaluasi pembelajaran yang telah disampaikan oleh guru terhadap anak didiknya. Biasanya ujian dilaksanakan setiap

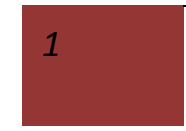


akhir materi, pertengahan semester dan akhir semester untuk menguji siswa dalam mendapatkan nilai yang baik untuk kelulusan sebuah mata pelajaran.

Sekolah Menengah Kejuruan (SMK) Indonesia Global adalah salah satu sekolah di wilayah Depok yang membutuhkan suatu pembelajaran yang fleksibel dan terdistribusi. Dalam proses penilaian ujian SMK Indonesia Global masih memakai cara konvensional yaitu pada ujian baik ujian tengah semester (UTS) maupun ujian akhir semester (UAS) masih dilakukan dengan membagikan soal dalam bentuk kertas, kemudian siswa mengisi atau menjawab soal dilembar jawaban yang telah disediakan. Dengan dilaksanakanya ujian yang konvensional muncul berbagai permasalahan yang berakibat sering terlambatnya penerimaan raport hasil ujian dikarenakan guru mengalami kendala waktu dan tenaga dalam mengoreksi jawaban siswa satu persatu dalam bentuk kertas. Permasalahan yang lain yang terjadi dari kondisi lembar jawaban yang sudah dijawab oleh siswa sering mengalami kehilangan bahkan kerusakan akibat penyimpanan kurang aman dan tidak teratur.

Berdasarkan permasalahan tersebut maka diperlukan penerapan teknologi informasi untuk mengatasi masalah tersebut, dengan membuat perancangan sistem ujian berbasis web untuk memudahkan guru dalam membuat soal dan mengoreksi jawaban siswa sehingga mempercepat dalam pembuatan laporan nilai anak didiknya.

\section{TINJAUAN PUSTAKA}

\subsection{Sistem Informasi}

Menurut Mustakini "Sistem adalah suatu jaringan kerja dari prosedur - prosedur yang saling berhubungan, berkumpul bersama-sama untuk melakukan suatu kegiatan atau untuk menyelesaikan suatu sasaran yang tertentu" (Lubis, 2016).

Sedangkan "Sistem Informasi adalah kumpulan dari sub-sub sistem yang saling terintegrasi dan berkolaborasi untuk menyelesaikan suatu masalah dengan cara mengolah data menggunakan komputer sehingga dapat menjadi nilai tambah bagi pengguna" (Rohmat, 2013).

\subsection{Website}

Menurut Raharjo "website adalah suatu layanan di dalam jaringan internet yang berupa ruang informasi" (Rahmatullah, Purnia, \& Triasmoro, 2019).

\subsection{HTML}

"HTML (Hypertext Markup Language) adalah sebuah protokol yang digunakan untuk membuat format suatu dokumen website yang mampu dibaca dalam browser dari berbagai platform komputer"(Sugiri, 2007).

\subsection{PHP}

"PHP adalah bahasa pemograman yang dijalankan melalui halaman web, umumnya digunakan untuk mengolah informasi di internet" (Kurniawan, 2010). Sedangkan dalam pengertian lain PHP adalah singkatan dari PHP: Hypertext Preprocessor yaitu bahasa pemrograman web server-side yang bersifat open source atau gratis. PHP merupakan script yang menyatu dengan HTML dan berada pada server (server side HTML embedded scripting).

\subsection{Mysq1}

"MySQL adalah salah satu jenis database server yang sangat terkenal dan banyak digunakan untuk membangun aplikasi web yang menggunakan database sebagai sumber dan pengolahan datanya"(Arif, 2011).

\subsection{Model Pengembangan Perangkat Lunak}

Menurut Sukamto dan Shalahuddin "Model SDLC air terjun (waterfall) sering juga disebut model sekuensial linier (sequential linear) atau alur hidup klasik (classic life cycle)"(Dermawan \& Hartini, 2017).

Berikut adalah gambar model air terjun:

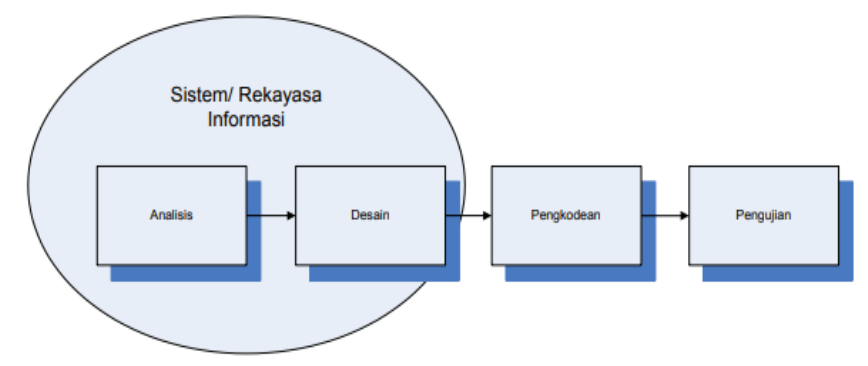

Sumber: Sukamto dan Shalahuddin (2013)

Gambar 1. Model Waterfall

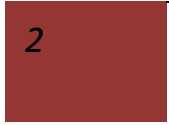




\subsection{ERD (Entity Relationship Diagram)}

"ERD adalah alat pemodelan data utama dan akan membantu mengorganisasi data dalam suatu proyek ke dalam entitas- entitas dan menentukan hubungan antar entitas" (Simarmata \& Paryudi, 2010). Dengan penggunaan Entity Relationship Diagram dalam bentuk gambar dapat mempermudah dalam menganalisa kebutuhan suatu basis data dalam sebuah sistem yang akan dibangun dengan lebih cepat dan mudah.

\section{METODOLOGI}

Dalam menunjang penyusunan penelitian ini, maka penulis menggunakan metode pengembangan perangkat lunak dan pengumpulan data-data yang dibutuhkan sebagai berikut:

\subsection{Metode Pengembangan Perangkat Lunak}

Metode yang digunakan pada pengembangan perangkat lunak perancangan sistem informasi ujian berbasis web menggunakan model waterfall. Tahapan tahapan model waterfall (Sukamto \& Shalahuddin, 2013) adalah:

1. Analisis Kebutuhan Perangkat Lunak

Dalam analisa kebutuhan ini bertujuan untuk menganalisis kebutuhan yang dibutuhkan dalam perancangan baik berupa dokumen maupun sumber lain yang dapat membantu dalam menentukan solusi permasalahan yang ada.

2. Desain

Dalam Desain perangkat lunak menggunakan permodelan basis data dengan menggunakan ERD (Entity Relationship Diagram).

3. Pembuatan Kode Program

Dalam tahapan ini perancangan sistem baru dibuat dengan menggunakan aplikasi Adobe dreamweaver CS6 sebagai bahasa pemrograman dan mysql untuk membuat database serta xampp sebagai penghubung server database.

4. Pengujian

Pada tahapan ini pengujian program dilakukan dengan menggunakan BlacBox Testing dengan harapan bahwa perancangan yang sudah dibuat dapat berjalan dengan sesuai kehendak.

5. Pendukung (Support) atau Pemeliharaan
Dalam proses pemeliharaan ini penulis mengupayakan pengembangan sistem yang telah di rancang terkait software dan hardware dapat dibuat maksimal agar aplikasi dapat berjalan dengan baik.

\subsection{Teknik Pengumpulan Data}

Dalam pengumpulan data yang digunakan dalam pembuatan sistem informasi ujian berbasis web pada sekolah menengah kejuruan Indonesia Global sebagai berikut:

1. Metode Pengamatan langsung ( Observasi )

Penulis melakukan pengamatan langsung datang ke tempat penelitian yaitu SMK Indonesia Global yang beralamat di Jl. Kav DPR No. 110, Serua, Bojongsari, Depok, untuk mendapatkan data yang diteliti penulis melakukan analisa dan evaluasi terhadap masalah yang berkaitan dengan topik yang akan dibahas yaitu mengenai pelaksanaan ujian.

2. Metode Wawancara (Interview )

Untuk melengkapi hasil observasi, penulis melakukan metode wawancara atau tanya jawab untuk mendapatkan suatu data. Penulis juga melakukan tanya jawab secara lisan kepada Wakil bidang Kurikulum yang berhubungan langsung mengenai masalah pelaksanaan Ujian.

3. Metode Studi Pustaka ( Library )

Selain melakukan observasi dan wawancara penulis juga mencari data dengan cara studi pustaka. Dalam metode ini penulis berusaha untuk mempelajari buku-buku yang berkaitan dengan judul yang diambil. Sehingga penulis mendapatkan gambaran secara teoritis yang berguna untuk membantu penganalisaan dan perancangan maupun penulisan penelitian ini.

\section{HASIL DAN PEMBAHASAN}

\subsection{Analisis Kebutuhan}

A. Kebutuhan Pengguna

Dalam penelitian pembuatan ujian pada sekolah menengah kejuruan Indonesia Global yang penulis rancang merupakan sistem informasi berbasis web yang dapat digunakan oleh beberapa pengguna. Adapun spesifikasi kebutuhan dari aplikasi ujian berbasis web sebagai berikut:

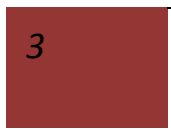




\section{A.1. Adminstrasi}

1. Dapat mengelola data siswa.

2. Dapat mengelola data guru.

3. Dapat mengelola data matapelajaran.

4. Dapat melihat soal ujian.

5. Dapat melihat hasil ujian siswa.

\section{A.2. Guru}

1. Dapat mengelola soal ujian.

2. Dapat mengelola ujian.

3. Dapat melihat hasil ujian siswa.

\section{A.3. Siswa}

1. Dapat melakukan ujian.

2. Dapat melihat hasil ujian.

\section{B. Kebutuhan Pengguna}

1. Penguna harus melakukan login terlebih dahulu untuk dapat mengakses website ujian dengan memasukan username dan password sesuai hak akses masing-masing.

2. Penguna harus melakukan logout setelah selesai mengakses program.

3. Sistem mengkalkulasi dan memperbarui data serta menyimpan perubahan data yang terjadi yang telah dilakukan oleh pengguna.

\subsection{ERD (Entity Relationship Diagram)}

Dalam pembuatan basis data dalam perancangan sistem informasi ujian berbasis web pada sekolah menengah kejuruan Indonesia Global sebagai berikut:

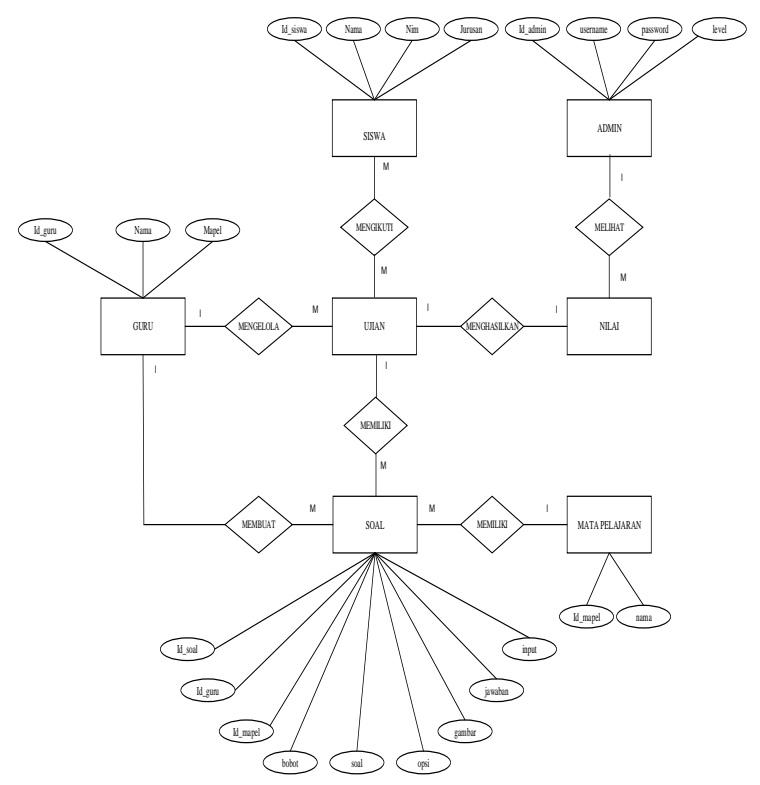

Sumber: Hasil Penelitian (2018)

Gambar 2. Entity Relationship Diagram

\subsection{Implementasi Antar Muka}

\section{A. Halaman Login}

Semua pengguna baik adminstrator, guru maupun siswa harus melakukan login terlebih dahulu agar dapat menggunakan modul - modul yang tersedia.

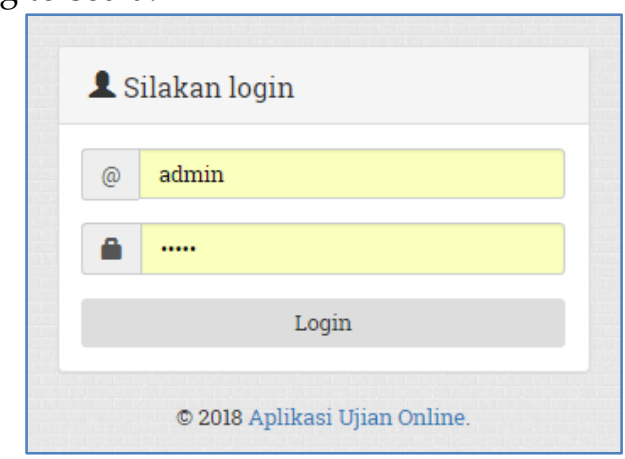

Sumber: Hasil Penelitian (2018)

Gambar 3. Halaman Login

B. Halaman Utama Administrator

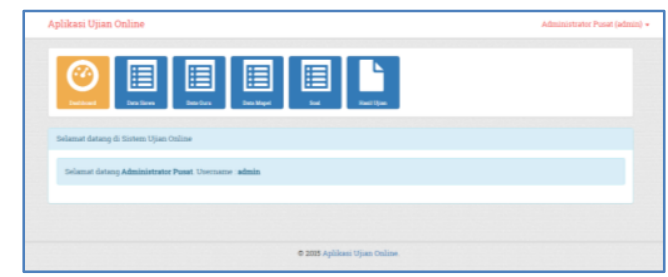

Sumber: Hasil Penelitian (2018)

Gambar 4. Halaman Utama Administrator

C. Halaman Manajemen Siswa

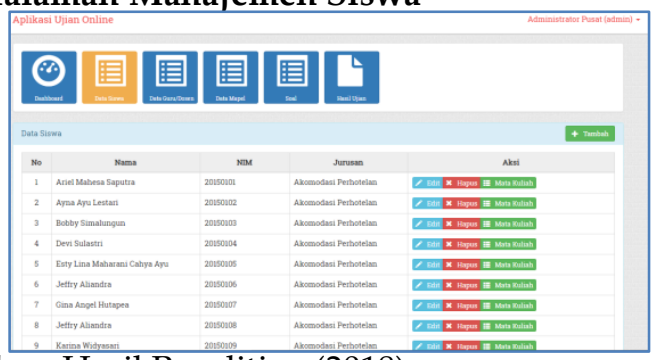

Sumber: Hasil Penelitian (2018)

Gambar 5. Halaman Manajemen Siswa

D. Halaman Manajemen Guru

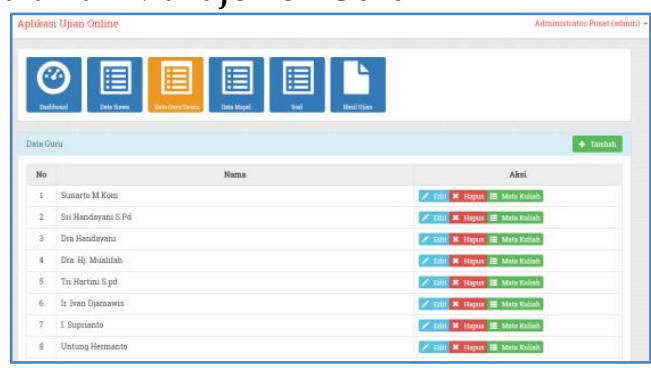

Sumber: Hasil Penelitian (2018)

Gambar 6. Halaman Manajemen Guru

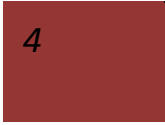


E. Halaman Mata Pelajaran

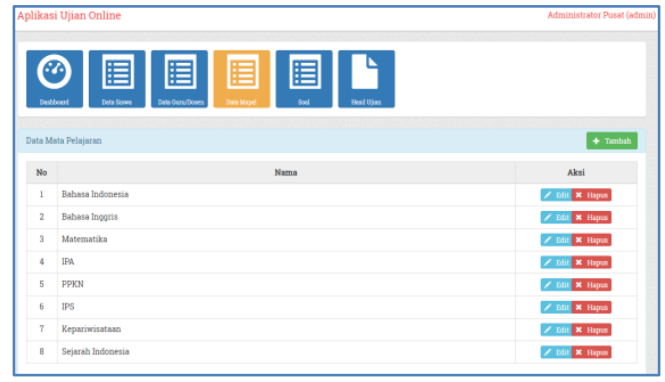

Sumber: Hasil Penelitian (2018)

Gambar 7. Halaman Mata Pelajaran

\section{F. Halaman Utama Guru}

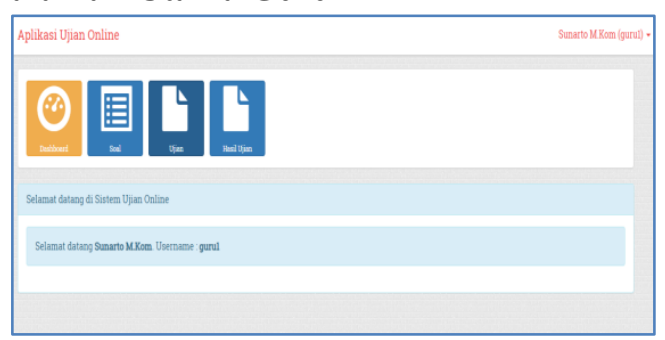

Sumber: Hasil Penelitian (2018)

Gambar 8. Halaman Utama Guru

\section{G. Halaman Data Soal}

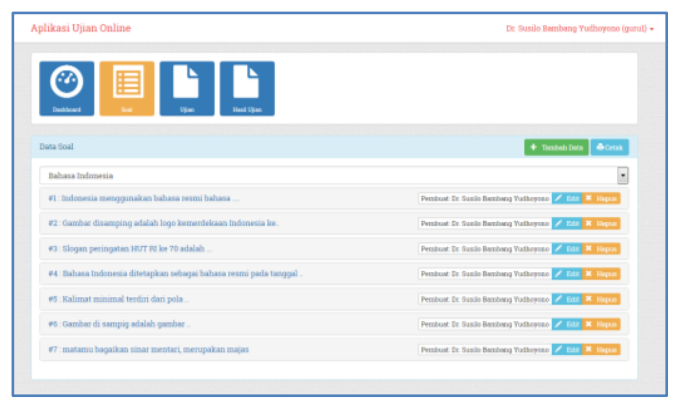

Sumber: Hasil Penelitian (2018)

\section{Gambar 9. Halaman Data Soal}

\section{H. Halaman Hasil Ujian}

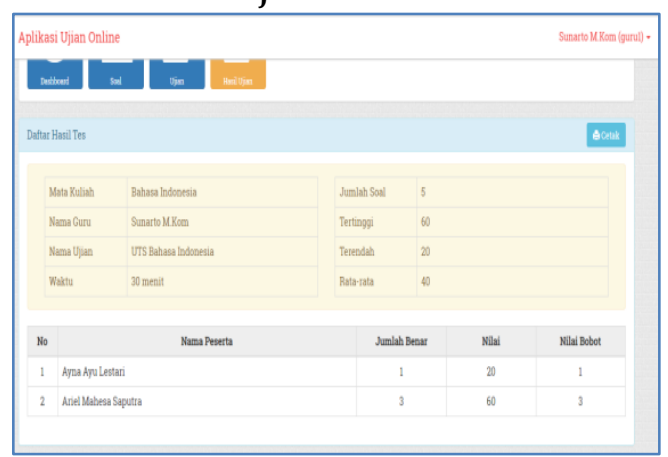

Sumber: Hasil Penelitian (2018)

Gambar 10. Halaman Hasil Ujian

\section{Halaman Ujian Siswa}

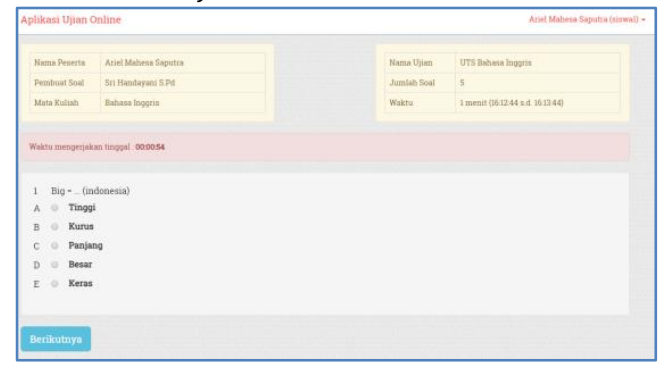

Sumber: Hasil Penelitian (2018)

Gambar 11. Halaman Ujian Siswa

\section{KESIMPULAN DAN SARAN}

Dari hasil penelitian pada sekolah menengah kejuruan Indonesia Global Depok ada beberapa kesimpulan yang dapat dikemukakan sebagai berikut:

1. Penggunaan metode waterfall dapat digunakan dengan baik dalam perancangan ujian berbasis web karena dalam pengerjaan masing-masing tahapan dikerjakan tidak bersamaan dengan tahapan yang lain sehingga dapat fokus dalam pengerjaannya.

2. Pemanfaatan informasi berbasis website dapat memberikan solusi masalah dalam dunia pendidikan terutama dalam ujian siswa pada SMK ndonesia Global.

3. Sistem informasi ujian berbasis web yang dirancang dapat membantu guru dalam membuat soal ujian dan mempermudah dalam mengelola nilai ujian siswa dengan cepat dan tepat.

4. Sistem informasi ujian berbasis web yang dibuat bersifat intern, artinya pengguna program ini hanya kalangan tertentu yang memiliki hak akses terhadap sistem yaitu siswa, guru, dan administrator.

Dalam pembuatan ujian berbasis web pada SMK Indonesia Global masih memiliki beberapa kekurangan yang harus disempurnakan sehingga penulis menyaranakan untuk pengembangan selanjutnya sebagai berikut:

1. Dalam perancangan tampilan dibuat lebih interaktif dengan penambahan fitur quis dengan pembahasannya.

2. Untuk platform tidak hanya dalam website namun bisa berupa aplikasi yang dapat berjalan di smartphone seperti android atau IOS. 


\section{REEFERENSI}

Arif, M. R. (2011). Pemrograman Web Dinamis Menggunakan PHP dan MySQL. Yogyakarta: Andi Offset.

Dermawan, J., \& Hartini, S. (2017). Implementasi Model Waterfall Pada Pengembangan Berbasis Web Pada Sekolah Dasar Al-Azhar Syifa Budi Jatibening. Paradigma, 19(2), 142147.

Kurniawan, R. (2010). PHP \& MySQL untuk Orang Awam. Palembang: Maxikom.

Lubis, B. O. (2016). Sistem Informasi Penjualan Voucher Belanja Pada PT. Plaza Iindonesia Reality Tbk. Jakarta. Jurnal Informatika, III(1), 51-62.

Rahmatullah, S., Purnia, D. S., \& Triasmoro, R.
(2019). Analisis Kualitas Website Sekolah North Jakarta Intercultural School dengan Metode Webqual 4 . 0.19(2).

Rohmat, T. (2013). Sistem Informasi Manajemen. Yogyakarta: Graha Ilmu.

Simarmata, J., \& Paryudi, I. (2010). Basis Data. Yogyakarta: Andi.

Sugiri. (2007). Desain Web Menggunakan HTML + CSS,. Yogyakarta: Andi Offset.

Suharyanto, \& Mailangkay, A. B. L. (2016). Penerapan E-Learning Sebagai Alat Bantu Mengajar Dalam Dunia Pendidikan. Jurnal Ilmiah Widya, 3, 17-21.

Sukamto, R. A., \& Shalahuddin, M. (2013). Rekayasa Perangkat Lunak Terstruktur dan Berorientasi Objek. Bandung: Informatika. 